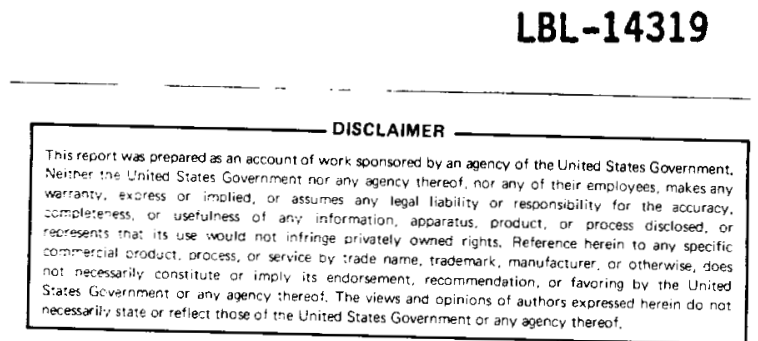

\title{
DEEP ELECTROMAGNETIC SOUNDING IN CENTRAL NEVADA
}

\section{by}

M. Wilt, N.E. Goldstein, J.R. Haught, and H.F. Morrison

\author{
Earth Sciences Division \\ Lawrence Berkeley Laboratory \\ University of California \\ Berkeley, California 94720
}

\section{April 1982}

This work was supported by the Director, Office of Energy Research, Office of Basic Energy Sciences, Division of Engineering, Mathematics and Geosciences, of the U.S. Department of Energy under Contract DE-AC03-76SF00098. 


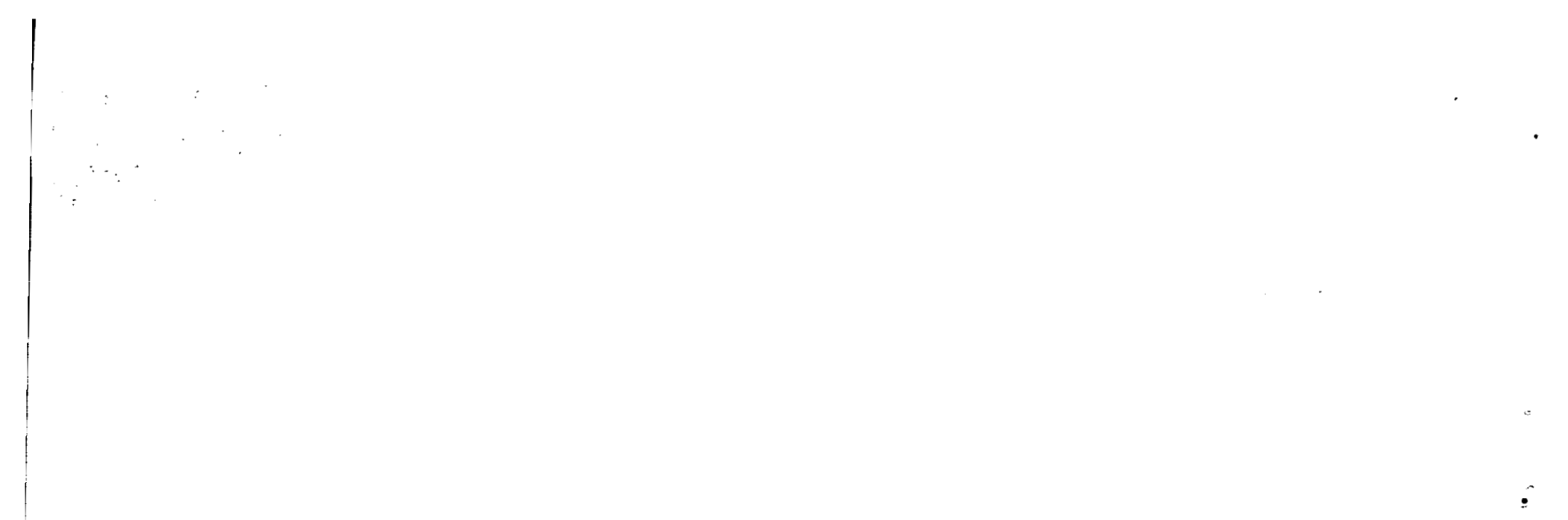

$\therefore \therefore$ 


\section{DISCLAIMER}

This report was prepared as an account of work sponsored by an agency of the United States Government. Neither the United States Government nor any agency Thereof, nor any of their employees, makes any warranty, express or implied, or assumes any legal liability or responsibility for the accuracy, completeness, or usefulness of any information, apparatus, product, or process disclosed, or represents that its use would not infringe privately owned rights. Reference herein to any specific commercial product, process, or service by trade name, trademark, manufacturer, or otherwise does not necessarily constitute or imply its endorsement, recommendation, or favoring by the United States Government or any agency thereof. The views and opinions of authors expressed herein do not necessarily state or reflect those of the United States Government or any agency thereof. 


\section{DISCLAIMER}

Portions of this document may be illegible in electronic image products. Images are produced from the best available original document. 
DEEP ELECTROMAGNETIC SOUNDING IN

CENTRAL NEVADA

M. Wilt, N.E. Goldstein, J.R. Haught and H.F. Morrison

ABSTRACT

Sixteen shallow and deep controlled source electromagnetic soundings were performed in Buena Vista Valley, near Winnemucca, Nevada, to investigate an intra-basement conductor previousiy detected with magnetotellurics. The survey was carried out with the LBL EM-60 system using a remote magnetic reference for low-frequency geomagnetic no ise cancellation, 100-m- and 2.8-km-diameter transmitter loops, and a minicomputer for in-field processing. EM soundings were made at distances from 0.5 to $30 \mathrm{~km}$ from three loops over the frequency range 0.02 to $500 \mathrm{~Hz}$. Data were interpreted by means of 1-D inversions and the resulting layered models were pieced together to yield an approximate 2-D geoelectric model al ong the $\mathrm{N}-\mathrm{S}$ axis of the valley. The EM soundings and one MT sounding show a 3 to $7 \mathrm{ohm}-\mathrm{m}$ zone at a depth of four to seven $\mathrm{km}$. The conductor appears to be deepest at the northern end of the valley and shallowest beneath a basement ridge that seems to divide Buena Vista Valley into two basinal structures. Similar intra-basement conductors are also reported 50-75 miles south in the Carson sink-Fallon areas, suggesting a common source, probably related to an anomalously hot, thin crust.

\section{INTRODUCTION}

During the Spring of 1981 a deep electromagnetic sounding survey was undertaken by Lawrence Berkeley Laboratory (LBL) in Buena Vista Valley, Nevada to confirm the presence of a relatively shallow intra-basement conductor, first detected with magnetotelluric measurements, and to delineate the conductor by means of the LBL controlled-source system, modified for deep sounding work. Shallow crustal conductors have been reported at various places within the Basin and Range Province and they are presumed related to the heat source that causes numerous hot springs, high regional heat flow and widespread, epithermal gold and mercury mineralization. 
Sixteen controlled-source electromagnetic soundings and one magnetotelluric sounding were made in Buena Vista Valley, Pershing County, Nevada (Fig. 1). The EM soundings were made relative to three loop sources with source-receiver separations ranging from 0.5 to $30 \mathrm{~km}$. Two of the loops were four-turns and $100 \mathrm{~m}$ in diameter, similar to those we have previously used for investigations to depths of about $2 \mathrm{~km}$. The other was a $6.25 \mathrm{~km}^{2}$, single-turn, large-moment source capable of providing signal for deeper exploration. This 1 arge-diameter source had a moment of $2 \times 10^{8} \mathrm{MKS}$, approximately 80 times greater than the smaller loops.

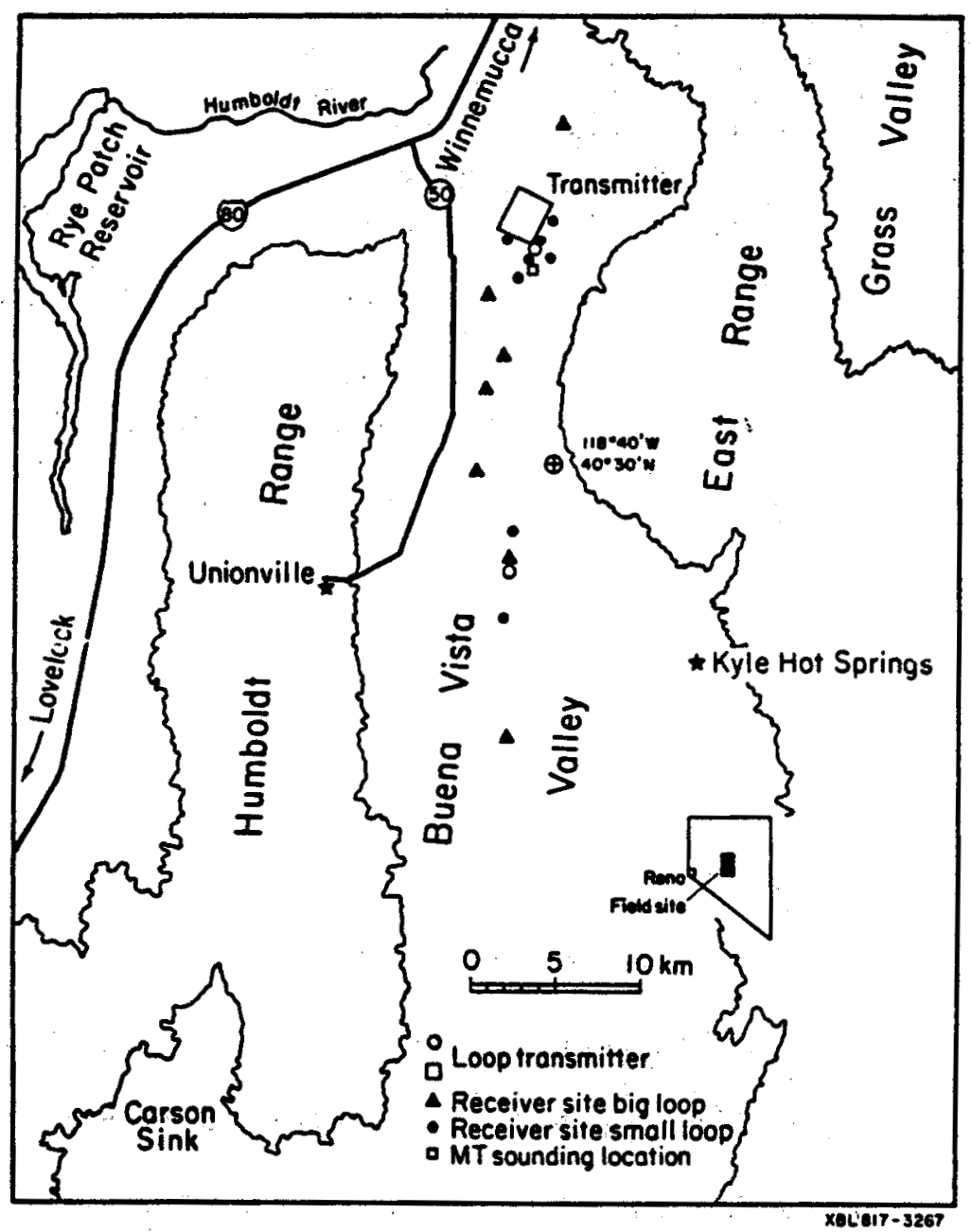

Figure 1. Location Map of the Deep Electromagnetic Soundings, Buena Vista Valley, Pershing Co., Nevada

Features of the system, shown schematically in Figure 2, include an eightchannel multiplexer, a two-channel digital oscilloscope for digitization, 
storage and display, and an HP 9835 minicomputer for data processing. Phase reference between loop current and observed magnetic fields was maintained by means of oven-controlled quartz clocks.

A remote reference magnetometer, shown in the upper right corner of Figure 2, was used for noise cancellation during both the MT and controlledsource EM surveys. The MT noise cancellation technique was described by Gamble et al. (1979). In the controlled-source work, a distant reference magnetometer provides signals to buck-out the natural geomagnetic variations at the receiver station. Our experience shows that a simple procedure of analog scalar subtraction performed with the transmitter off will reduce the geomagnetic "noise" by about 20db; thereby extending the useful frequency range down to $\sim 0.02 \mathrm{~Hz}$. The more elegant noise cancellation technique based on finding the tensor coefficients did not work as well because of the large amount of time needed to obtain the coefficients, and the instability of the coefficients over longer time intervals.
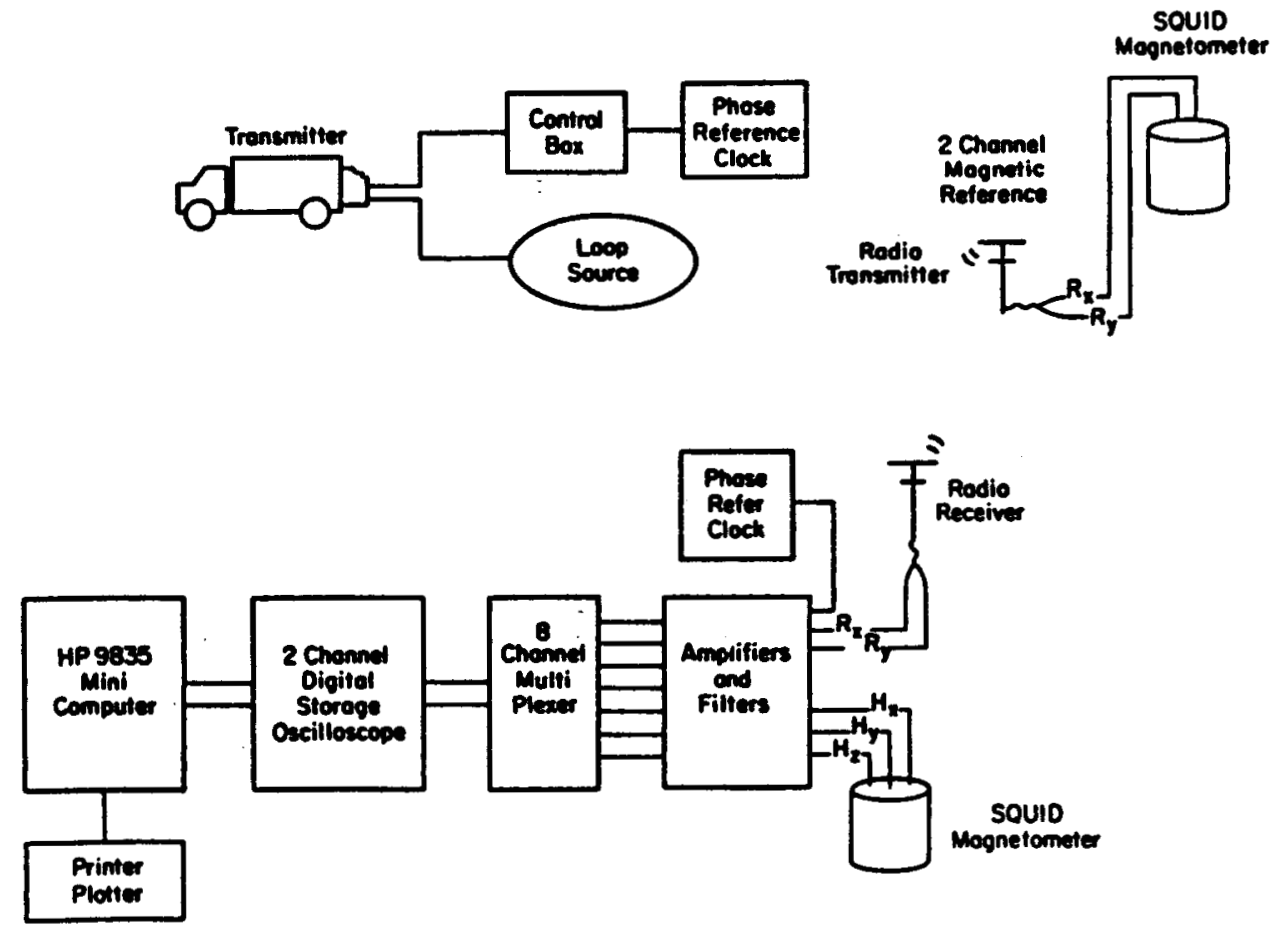

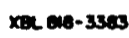

Figure 2. Schematic diagram of the EM-60 Controlled-Source EM System. 


\section{RESULTS}

We performed 1-D inversions on all 16 electromagnetic soundings and the one magnetotelluric sounding. The data for most stations fitted well to 1-D models, and these layered-models were reasonably consistent from station to station (Fig. 3).

The low resistivity $(10-20 \mathrm{ohm}-\mathrm{m})$ of the upper $\mathrm{km}$ presents some problems for deep electromagnetic sounding. Although signals could be received at up to $30 \mathrm{~km}$ from the source, the higher frequencies were severely attenuated by the conductive surface layer, making it impossible for us to get useable data above about $5 \mathrm{~Hz}$ when source-receiver separations exceeded $15 \mathrm{~km}$. The low resistivity surface also limited penetration of electromagnetic waves, thus making low frequency data collection mandatory. Without noise cancellation, collection at low frequency data would have been very difficult.

N

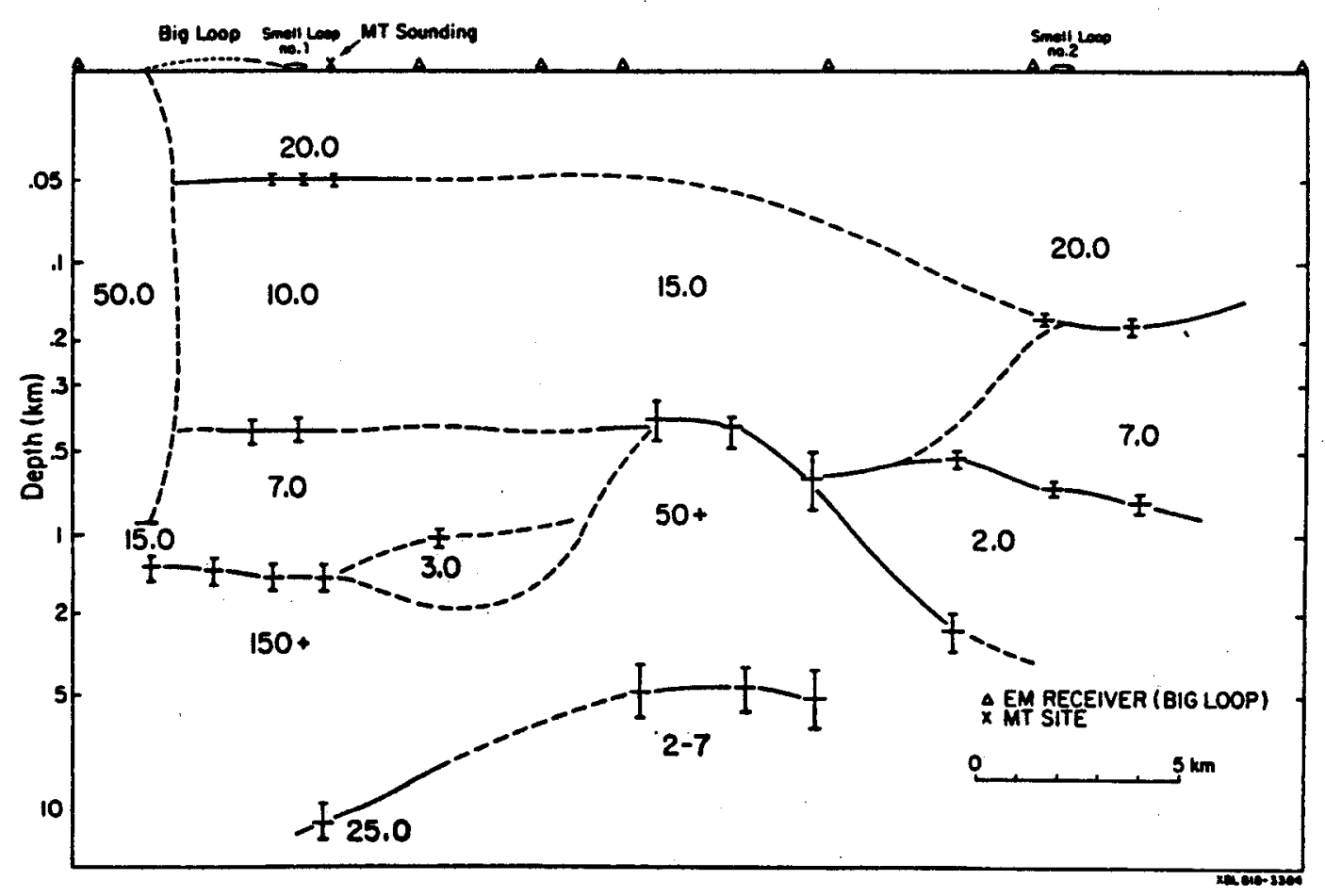

Figure 3. Geolectric cross-section showing interpreted resistivities along the axis of Buena Vista Valley, Pershing Co., Nevada. Error bars are the standard error for the layer thicknesses. 
Figure 3 is a composite of 1-D interpretations along anorth-south line paralleling the valley. According to our convention, the layered-model interpretation is plotted at a point midway between the transmiter and the receiver. The resistivity cross-section reveals that the shallow portion of the crust beneath Buena Vista Valley can be approximated by four or five layers. The parameters of the top layer are resistivity of $20 \mathrm{ohm}-\mathrm{m}$ and a thickness of between 50 and $200 \mathrm{~m}$. These parameters seem to be fairly consistent at most locations in the valley. This layer most likely represents partially saturated Quaternary alluvium. The second layer is some 200 to $500 \mathrm{~m}$ thick and approximately $10 \mathrm{ohm}-\mathrm{m}$ in resistivity. This unit is thickest in the northern and southern parts of the valley and may be absent in the center of the valley; it likely represents saturated Tertiary sediments and volcanics. Deeper parts of the section indicate conductive sediments overlying resistive basement. Basement depth ranges from 0.5 to $2.5 \mathrm{~km}$ with a basement high which suggests that the valley may be subdivided structurally into two basins, a northern one 1 to $1.5 \mathrm{~km}$ deep and a southern one 2 to $2.5 \mathrm{~km}$ deep. The resistivity of the basement is poorly resolved with EM and MT soundings because it carries relatively little current and therefore does not contribute greatly to the received signals.

Evidence for a conductor within the basement was found on three electromagnetic soundings and the MT sounding. For the EM soundings, a good electrical conductor ( 3 to $7 \mathrm{ohm}-\mathrm{m}$ ) was indicated 4 to $7 \mathrm{~km}$ beneath the central portion of the valley. The MT sounding indicated a good conductor (approximately $25 \mathrm{ohm}-\mathrm{m}$ ) $11 \mathrm{~km}$ in depth beneath the northern end of the valley. Fifty to 75 miles to the south in the Carson Sink, experiments by Keller et al. (1981) and by the U.S.G.S. (Stanley et al., 1976) have indicated conductors at about $5 \mathrm{~km}$ in depth. It is tempting, therefore, to speculate 
on whether the conductors are related geologically, constituting a regional feature. On the basis of geothermal evidence, Stanley et al. (1979) have proposed that the conductor is caused by Tertiary and pre-Tertiary marine sediments saturated with water at $150^{\circ} \mathrm{C}$ or greater and with salinities of about $20,000 \mathrm{ppm}$. The widespread occurrence of the conductor seems to confirm that a broad area of the shallow crust is anomalously hot.

Al though there are other surveys supporting the intra-basement conductor, our subsurface electrical model is only preliminary. The irregular valley shape, variable basement depth and the anomalously small radial fields and large tangential fields observed suggest 3-D complexities. 2-D modeling suggests that the depth to the conductor may be underestimated in the 1-D inversions.

\section{ACKNOWLEDGEMENT}

The work was supported by the Director; Office of Energy Research, Office of Basic Energy Sciences, Division of Engineering, Mathematics and Geosciences of the U.S. Department of Energy under Contract DE-ACO3-76SF00098.

\section{REFERENCES}

Keller, G.V., Tayl or, K., and Souto, J.M., 1981. Megasource EM method for detection of deeply buried conductive zones in geothermal exploration (Abst): Geophysics, v. 47, p. 420.

Stanley, W.D., Wahl, R.R., and Rosenbaum; J.G., 1976, A magnetotelluric study of the Stillwater-Soda Lakes, Nevada geothermal area: U.S. Geological Survey, Open-File Report 76-80, 38 p.

Gamble, T.D., Goubau, W.M., and Clarke, J. 1979, Magnetotellurics wi th a remote reference: Geophysics, v. 44, p. 53-68. 